\title{
Propuesta documental para la realización televisiva comunitaria
}

Por: Lic. Eduardo Alejandro Hernández Alfonso', Universidad Central Marta Abreu de Las Villas, Cuba, y Lic. Luis Ernesto Paz Enrique², Universidad Central Marta Abreu de Las Villas, Cuba.

Recibido: 17 de enero, 2017.

Aceptado: 18 de mayo, 2017.

\section{Resumen}

La producción televisiva comunitaria construye ofertas de información ancladas en postulados netamente populares, donde se desdeña la posición del usuario en la construcción de espacios de comunicación, en algunos casos. En este artículo ser determinan referentes teóricos-metodológicos de la televisión comunitaria y se propone un nuevo enfoque para su producción, a partir de postulados pertenecientes a las ciencias de la información. El estudio clasifica como teórico con enfoque cualitativo. Se emplean métodos en el nivel teórico y empírico para la recogida de información. Se analizan los descriptores de contenido presentes en los audiovisuales como factores intrínsecos de los materiales. Se identifica el análisis documental y se propone el empleo de los descriptores de resumen, topográficos, cronológicos, temáticos, onomásticos y de forma, para la realización televisiva comunitaria. Se concluye que la producción audiovisual en la televisión comunitaria puede sustentarse en referentes teórico-metodológicos planteados por las ciencias de la información y la comunicación social. De esta forma, se propone un nuevo enfoque para la producción audiovisual comunitaria.

\section{Abstract \\ DOCUMENT PROPOSAL FOR THE CREATION OF COMMUNITY TV}

The production of community TV in some cases provide opportunities for information anchored in purely popular principles, which disdains the position of the viewer in the building up of communication spaces. Theoretical-methodological references of community TV are determined, and a new approach for its production are proposed departing from principles of communication sciences. The study classifies as theoretical the qualitative approach. Empirical and theoretical methods are used in order to collect the information. The content descriptors present in the audiovisuals are analyzed as intrinsic factors of the materials. The document analysis is identified and the use of summary, topographical, chronological, thematic onomastic and formal descriptors is proposed for the production of community TV. The conclusion is that community TV can be sustained on theoretical-methodological references posed by information sciences and social communication. A new approach for the production of community audiovisuals is proposed.

1 Eduardo Alejandro Hernández Alfonso es Licenciado en Comunicación Social y Doctorante en Ciencias Sociológicas en la Universidad Central Marta Abreu de Las Villas. Labora como investigador en esa misma casa de estudios. Contacto: ealejandro@uclv.cu.

2 Luis Ernesto Paz Enrique es licenciado en Ciencias de la Información y Doctorante en Ciencias Sociológicas de la Universidad Central Marta Abreu de Las Villas. Se desempeña como académico en esa misma universidad. Contacto: luisernestope@uclv.cu.
Eduardo Alejandro Hernández Alfonso y Luis Ernesto Paz Enrique. Propuesta documental para la realización televisiva comunitaria. Revista Comunicación. Año 38, volumen 26, número 1, enero - junio, 2017. Instituto Tecnológico de Costa Rica. ISSN: 0379-3974 I e-ISSN: 1659-3820.
PALABRAS CLAVE:

educación sobre medios de comunicación, competencias profesionales, control terminológico, procesamiento de la información, televisión, comunidad.

KEY WORDS:

education on mass media, professional competences, terminology control, information processing, TV, community. 


\section{INTRODUCCIÓN ${ }^{3}$}

A partir del surgimiento de la televisión, múltiples han sido los estudios desarrollados con el objetivo de caracterizar el medio: "Desde la década de 1980 la comunicación se muestra bajo un modelo democrático, dialógico y horizontal que permite ejercer mecanismos de resistencia frente a las culturas dominantes" (Herrera y Uruburu, 2010, p. 212). El desarrollo de la ciencia, desde la epistemología comunicativa y de la información, se ha referido múltiples tipologías y enfoques.

Resulta indiscutible la influencia que ejerce la televisión en los usuarios. Su popularidad lo ha convertido en agente socializador de la información y del conocimiento. Los investigadores Aguaded, Hernando y Peréz (2012) sostienen que cuanto más se consume la comunicación a gran escala, más se siente la existencia de una profunda crisis comunicativa. Los mensajes de bien público dentro del esquema MASS-Media (medios de difusión masivos), aunque no han sido los más favorecidos, constituyen un importante generador de cambio social.

El fenómeno televisivo presenta múltiples facetas de interés general para los individuos. La característica de la televisión es la de ser un medio de comunicación de masa en la que se concentra numerosos y variados intereses de acuerdo con la programación transmitida "es un ecosistema social y cultural" (Aguaded y Díaz, 2008, p. 126). Las funciones del medio se refieren a las tipologías: comercial, expresiva, educativa, propagandística y publicitaria. "La Publicidad Social produce, distribuye y promueve campañas en nombre de organizaciones sin ánimo de lucro y de agencias gubernamentales sobre temas relacionados con la salud preventiva, la preservación del medioambiente, el bienestar social, etc." (Feliú, 2000, p. 3). En los estudios sociales realizados en Chile se expone la usabilidad del medio televisivo por parte de los usuarios para satisfacer necesidades de información y entretenimiento (Fernández,

3 Este trabajo fue concebido en el contexto del proyecto: Sistema de Superación en las Televisiones Locales para potenciar el Proyecto de Desarrollo Local (SSTV), cuyo investigador principal es el Doctorante en Ciencias Sociológicas, Lic. Eduardo Alejandro Hernández Alfonso. El proyecto ha permitido fortalecer la gobernabilidad local y la relación de la televisión local en la representación del proceso de implementación de la estrategia de desarrollo local.
1994), por lo que el medio debe reflejar las características y aspiraciones de sus usuarios.

La televisión es un medio cuya función técnica es la trasmisión de documentos de tipo audiovisual. A partir de los lenguajes sonoros e icónicos procura formar, transformar y transmitir información al usuario. Sus textos crean dependencia a las ideas, opiniones y actitudes que rompen en la mayoría de los casos con creencias y costumbres.

\section{LOS USUARIOS DE INFORMACIÓN Y SUS NECESIDADES EN EL CONTEXTO TELEVISIVO COMUNITARIO}

Los documentos audiovisuales transmitidos en el marco televisivo, dentro de las sociedades de consumo, los componen los productores y no los usuarios. Cuanto más se consume la información a gran escala, más sentimos y vivimos una profunda crisis informativa porque el audiovisual ante todo potencia una nueva cultura de la imagen (Aguaded, Hernando y Peréz, 2012). La producción televisiva comunitaria debe producir audiovisuales en correspondencia con las necesidades de la comunidad en la que está enmarcada.

La misión del profesional de la información debe estar encaminada a la realización de servicios y productos centrados en el usuario que satisfagan sus necesidades de información. Estas dependen de la actividad laboral, disciplina, campo, área de interés, disponibilidad de facilidades y la posición jerárquica de los individuos (Crawford, 1997). Un servicio o producto de información o comunicación centrado en el usuario propiciará el intercambio, la colaboración (Manso, 2012) y el establecimiento de relaciones sociales.

A propósito de esto Rendón y Hernández (2010) dicen que "abordar el fenómeno usuario de la información ha requerido que los interesados en el tema sigan diferentes tendencias" (p. 74). Es determinante para el ofrecimiento de un producto, la identificación de su necesidad para garantizar el éxito. El diseño de productos centrados en las necesidades de los usuarios se revertirá en beneficio de la comunidad. Por su parte, Calva (2013) plantea que los usuarios son la razón por la cual la información debe conservarse, para empleo además de las siguientes generaciones y para promover el avance de la sociedad 


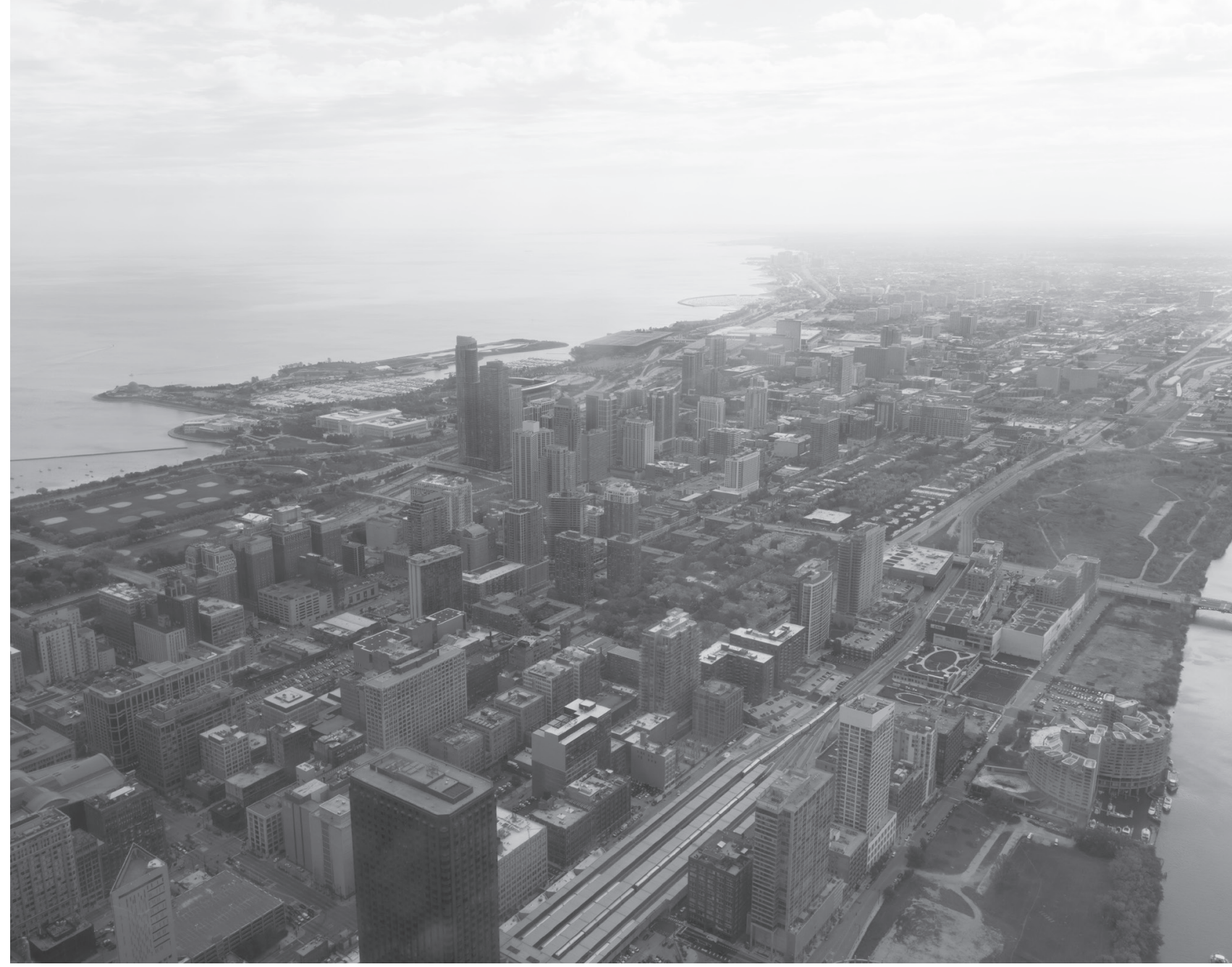

misma. La aplicación y ejecución de productos crea vínculos entre los especialistas y los usuarios mediados por una necesidad previa.

Wilson define que "una necesidad de información se constituye a partir de otras necesidades originadas en los diferentes contextos de la experiencia y la acción; a partir del contexto físico y biológico y de los contextos de trabajo, sociales, políticos, etcétera" (1999, p. 253). El mediador entre el usuario y el producto, debe ser un profesional capaz de dilucidar la necesidad real del usuario/cliente y procurar solucionar la problemática. Dervin y Nilan por ejemplo, defienden la concepción conocida como Sense Making, "la estrategia de interpretar la realidad y hacerla lógica, comprensible y significativa para el individuo" (1986, p. 27). Rey (2000) por su lado, plantea que "es mejor emplear como indicador de satisfacción de usuarios, la utilización efectiva de los servi- cios y productos, con lo que se otorga a los usuarios un papel activo en el proceso de transferencia de la información al considerarlo como un coproductor" (p. 140). El diseño de un servicio o producto de información o comunicación debe basarse en las características de sus usuarios potenciales y favorecer la creación de canales de retroalimentación que les permitan a los futuros usuarios la construcción colectiva de lo que luego van a consumir. Sobre las necesidades de información, las características de los usuarios y el diseño de productos se identifican varios autores como Belimpasakis y Saaranen (2010), Figueredo, Figueredo y Aponte (2013), González (2011), Harsh y Mishra (2012), Wang y Klinc (2012), Cabrera, Donoso, Aneas y del Campo (2010).

La televisión comunitaria tiene la misión de ser el medio televisivo más cercano al usuario y por ende debe ser un facilitador que refleje las características 
y aspiraciones de sus usuarios potenciales. La televisión comunitaria es el medio principal por el cual la comunidad se informa. El medio televisivo comunitario es el más cercano a los usuarios y debe, por tanto, ser el que más pueda satisfacer las necesidades de los usuarios a partir de la personalización de las necesidades informativas. La construcción colectiva de las parrillas televisivas o el diseño de productos y servicios basados en las características de los usuarios y la comunidad favorecerán la participación, el consumo y la usabilidad.

\section{LA TELEVISIÓN COMUNITARIA Y SU SISTEMA DE CÓDIGOS TEXTUALES}

La experiencia de la televisión comunitaria se desarrolla a todo lo largo de la región latinoamericana. Esta parte de un modelo comunicativo con la participación de la localidad desde el momento mismo de su instalación y constituye uno de los requisitos fundamentales para su reconocimiento entre la audiencia. Ninguna televisión comunitaria puede ser impuesta sobre los usuarios, sino que debe ser el resultado de una necesidad sentida. Sobre el medio televisivo comunitario se destacan varios autores, entre ellos Márquez (2013), Retis (2014) y Gumucio (2008).

Las características esenciales de la televisión comunitaria se resumen en el carácter dialógico y el intercambio real de los actores del espacio comunicativo; participación directa de los usuarios en los procesos productivos y por el contenido social, educativo y cultural de sus programaciones, influenciados por un fuerte contenido local y heterogéneo (Hernández, Paz y Jara, 2016). Se necesitan además otros elementos: mejores equipos de producción capaces de soportar el uso diario e intenso, más asesoramiento técnico especializado, metas de producción y difusión así como vinculación con las organizaciones comunitarias. El cumplimiento de los estándares de calidad en la programación y la especialización en las rutinas televisivas, no afectaría el objetivo esencial de la propuesta local y consolida el discurso contracultural ante los intereses homogenizantes de los consorcios televisivos.

Los canales comunitarios construyen, en muchos casos, ofertas informativas ancladas en postulados netamente populares, que desdeña la posición del usuario en la construcción de audiovisuales. El proceso se ejecuta desde la comunidad usuaria. Los resultados esperados deberían ocurrir a través de un crecimiento empírico hasta un grado de especialización superior, sin perder la esencia del trabajo colectivo en la representación del imaginario popular.

\section{METOdOLOGÍA}

El presente estudio se propone ofrecer una contribución teórica relevante en cuanto a la reflexión de la producción televisiva comunitaria a partir de aspectos descritos desde el análisis documental y del procesamiento de la información audiovisual en específico. La investigación contribuirá a la solución de múltiples cuestiones prácticas relativas a la producción televisiva comunitaria, potenciado que la misma esté centrada en el usuario. La consideración anterior favorecerá que los materiales audiovisuales producidos representen las características y aspiraciones de los usuarios. De esta forma se potenciará la construcción colectiva del conocimiento y la usabilidad de los documentos audiovisuales producidos.

La producción en las televisiones comunitarias presenta una estructura que puede ser significativamente mejorada a partir de elementos técnicos-formales y comunicativos. Se plantean como objetivos del estudio los dos siguientes:

A) Determinar referentes teórico-metodológicos que sustenten las estructuras técnico-formales de la televisión comunitaria a partir un análisis interdisciplinar.

B) Proponer un nuevo enfoque para la producción audiovisual en la televisión comunitaria centrada en el usuario a partir del procesamiento de la información audiovisual.

El estudio clasifica como investigación teórica con enfoque descriptivo. La temática ha sido estudiada por múltiples investigadores, pero se pretenden abordar los paradigmas teóricos de la televisión comunitaria desde una nueva perspectiva documental. El enfoque de la investigación es cualitativo, su objetivo principal está en la exposición de ideas y análisis del conocimiento sobre la temática a estudiar. Se 
utilizan múltiples métodos teóricos en el estudio por sus características:

- Lógico-histórico: se estructuran los contenidos jerarquizándolos a fin de una concreción lógica. Se emplea para estudiar el desarrollo lógico e histórico de los principales criterios sobre el tema.

- Analítico-sintético: posibilita el análisis por segmentos de las principales consideraciones que describen el fenómeno de la televisión comunitaria y el procesamiento de la información audiovisual. Se sintetizan conceptos, se brindan consideraciones y se asumen posturas en dependencia del criterio de especialistas en las temáticas abordadas.

- Inductivo-deductivo: los elementos particulares del tema de la investigación se toman como referencia, mediante la inducción analítica. Se inducen temáticas relativas al problema abordado, se toman posturas y se arriba a conclusiones totales y parciales.

- Sistémico-estructural: se realiza una estructuración y orden lógico a los contenidos que se presentan en la investigación. Se jerarquizan las temáticas teniendo en cuenta la generalidad de los conceptos y conocimientos que se abordan. Se organiza la información presentada partiendo de lo general a lo particular.

En el nivel empírico se empleó el análisis documental clásico. Las técnicas utilizadas fueron la revisión de documentos y la triangulación de información como vía para la validación de los resultados obtenidos.

\section{RESULTADOS}

El trabajo en conjunto de las ramas del conocimiento de la comunicación social y las ciencias de la información, ha propiciado nuevas interpretaciones de fenómenos comunes. La relación entre los saberes involucrados se fundamenta epistemológicamente desde el análisis documental y sus variantes o técnicas: análisis de contenido, indización y resumen. Estas herramientas brindan a la comunicación nuevas técnicas para el registro y análisis de los materiales audiovisuales. En el desarrollo de la sociedad de la información la integración de disciplinas científicas es un factor primordial para el logro de resultados con mayor impacto; "abrir las ciencias sociales" (Wallerstein, 2006) y permitir recoger resultados tangibles y desde diversas ópticas.

Se analizan también las teorías de Pinto, García y Agustín (2002) en el análisis de documentos audiovisuales y multimedia. Se utilizan los referentes connotacionales y denotacionales del mensaje audiovisual y el concepto texto para analizar la estructura retórica de los productos televisivos. Los investigadores Hjórland y Albrechtsen (2007) en sus métodos de análisis de dominio, mezclan la dimensión investigativa de la ciencia de la información, la comunicación social, el periodismo y la sociología. Las peculiaridades sintéticas y polisémicas de la imagen implican su rápida selección en la recuperación y flexibilidad en su utilización. Estas características derivan de su código icónico menos formalizado que el verbal.

La descripción de la imagen es intrínsecamente subjetiva en virtud de la separación entre lo que denota —el significado común del signo- y connota —el significado cultural del signo-. Con frecuencia, requiere del texto o el sonido para fijar su significado para su contextualización. Se debe percibir al usuario no como receptores o consumidores de información, sino como agentes transformadores.

La obtención de un producto audiovisual es posible por el tránsito exitoso de las rutinas televisivas: idear, evaluar, organizar, presupuestar, buscar financiación, realizar y controlar el cumplimiento de los objetivos. Para transcurrir por estas etapas es preciso conocer los elementos que intervienen en el proceso y que contribuyen al trabajo de todo el equipo técnico y artístico. El proceso de producción televisiva se puede sintetizar en su estructura básica: idea, imagen y sonido.

Las imágenes, del mismo modo que las palabras, poseen significado denotativo, designativo y connotativo. Las relaciones discursivas en el texto audiovisual definen la forma de interpretar cada signo. El criterio teórico usual establecido para los análisis semánticos aborda la denotación desde la literalidad mientras que la connotación se remite al valor simbólico. La semiótica "es un método que permite entender las prácticas culturales que implican necesariamente significados de diverso orden" (Barthes, 1976, p. 28). La preponderancia del discurso audiovisual está 
dada debido a que la percepción del mundo es obtenida en constantes imágenes, analizadas y decodificadas en cientos de significados. El proceso de producción de imágenes en la televisión está dado por la iteración de varias etapas. Cada fase posibilita que el mensaje visual sea elaborado de acuerdo con las exigencias de los objetivos trazados, sin obviar las mediaciones sociales que intervienen en el proceso de decodificación.

\section{EL TEXTO AUDIOVISUAL Y SU PROCESAMIENTO}

El lenguaje se basa, entre otros, en la designación para la representación de objetos. En los medios audiovisuales dicha relación se sintetiza en la tríada audio-escripto-icónico, pues el componente visual lo integran las imágenes y textos escritos y desde lo sonoro se hace referencia a textos leídos, música y ruidos (Cloutier, 2001, p. 35).

Según Menéndez y Hassan, el "lenguaje natural es un conjunto de signos y símbolos orales y escritos por medio de los cuales los seres humanos se comunican entre sí" (2007, p. 155). En este caso y siguiendo la línea conceptual de los autores, se definirá este tipo de lenguaje como el conjunto de palabras y material ideográfico utilizados por un autor para expresar sus ideas por medio de un documento. Los procesos de percepción de información audiovisual comprometen los siguientes eslabones: percepción de información y organización de la comunicación, ambos se sustentan de las actividades cognitivas inherentes a la comprensión y la memoria. Al decodificarse una imagen audiovisual se suscita un grupo de estrategias cognitivas que engloban la percepción y la memoria episódica.

Los especialistas Hernández (2007) y Pérez (2002) establecen que las relaciones entre el texto audiovisual y sus contenidos estriban en el punto de vista de la visión del mundo aplicado al objeto informativo. Otros especialistas abogan que "no depende exclusivamente de los productores o de los usuarios, sino de los significados culturales, históricos y colectivos contextualizantes que sus productores extraen para hacerla y de la que sus usuarios hacen uso para interpretarla" (Raber y Budd, 2003, p. 512). Intervienen en este proceso las asociaciones cognitivas hechas por las personas con respecto a una determinada in- formación. Esto hace que se plantee una respuesta a partir de la correspondencia de un determinado stock de información que logra asociarse con un conocimiento previo de una temática en específico.

La comprensión de un texto audiovisual parte de su visionado. Durante este proceso se jerarquizan y estructuran por palabras claves o temáticas el contenido del documento audiovisual. En la interacción y desarrollo de estos procesos cognitivos, prima lo que la gente recuerda de un texto audiovisual. No es tanto su significado, sino más bien el modelo que construyen acerca del hecho sobre el que trata el texto. Según el criterio de Van Dijk "la decodificación de los mensajes por parte de indizador/analista de información se realiza para el procesamiento del texto: mientras los modelos son personales, subjetivos y ad hoc (unidos al contexto actual del entendimiento), el conocimiento puede ser visto como una generalización y abstracción de tales modelos" (2004, p. 17).

Durante el visionado el documentalista debe leer las imágenes y crear una descripción textual. Se debe traducir en palabras el contenido visual y sonoro del material de la forma más objetiva posible, teniendo presente tanto el aspecto formal como el de contenido. Se trata no solo de ordenar aquello que el ojo percibe en muy pocos segundos sino de identificar los elementos. Para lo que es necesario poseer los referentes adecuados y las competencias establecidas por Senso, Magaña, Faber-Benítez y Vila, (2007): iconográfica, narrativa, estética, enciclopédica y lingüístico-comunicativa.

El comunicador y el documentalista (especialista en ciencias de la información), tienden invariablemente a analizar imágenes mediante términos abstractos. Al realizar estas acciones no se considera que una imagen pueda significar de forma unívoca, un término abstracto. Ello limita el proceso técnico documental e impide la reutilización de la imagen y sus múltiples significados. Resulta necesario el conocimiento de planos, encuadres, efectos de iluminación, movimientos de cámaras, entre otros aspectos.

Fijar la descripción de las imágenes es fundamental para un buen análisis y registro del documento audiovisual. Una descripción demasiado detallada -que pretenda describir todos los objetos y acciones reconocibles en cada plano-, es muy costosa. 




Como consecuencia de este proceso se provoca la ineficiencia del indizador y puede producir un exceso de ruido en la representación del mensaje. En el otro extremo, una descripción demasiado somera o selectiva provocará que los documentos no puedan ser recuperados y utilizados. Una descripción media debe incluir como mínimo el registro de las secuencias más relevantes, indicando los nombres de los personajes, la identificación de lugares y la descripción de las acciones que se desarrollan. El análisis debe omitir descripciones de imágenes de escaso interés documental (repetitivas) y registrar el código de tiempo (Arellano, 2014).

Es conveniente que el usuario y el analista compartan códigos similares. La identificación de los usuarios potenciales y finales favorecerá los procesos de indización. El análisis debe partir de las características de los usuarios para los que se procesan los documentos audiovisuales y las tipologías de géneros televisivos.

El análisis de contenido "es una forma de estudio de las particularidades de los mensajes, tanto escritos, como sonoros, audiovisuales, etc." (Hernández, 2007). Este método investigativo tiene su origen en las primeras descripciones empíricas de cono- cimiento, desarrolladas por Harter y Busha (1990) y Urías (2009) para el análisis de modelos de contenido con diversos fines: "El minutado describe y mide con precisión lo que sucede en el documento, traduciendo a frases la dimensión temporal del contenido, indicando la duración y contenido de cada escena" (Del Valle, 2014, p. 3).

La propuesta de registro del material audiovisual desde la perspectiva documental fue planteada por Pinto, García y Agustín (2002), estableciendo parámetros formales para el desarrollo del modelo minutado. El proceso cuenta de dos pasos fundamentales: el resumen del material audiovisual y la descripción por planos o secuencias de las escenas del documento. El resumen se establece con la declaración por parte del indizador de una serie de descriptores que favorecen la recuperación de los materiales. El objetivo de los descriptores a decir de Gil (2008) es identificar nombres propios de cosas (empresas, instituciones, marcas, etcétera).

A decir de Del Valle (2014) el análisis documental de materiales audiovisuales da lugar a tres productos diferentes:

- El resumen del documento, de carácter indicativo, que define en pocas frases de qué trata. 
- El minutado, que describe y mide con precisión lo que sucede en el documento, traduciendo a frases la dimensión temporal del contenido, indicando la duración y contenido de cada escena.

- Los descriptores, resultado de la indización, que expresan el contenido en un lenguaje controlado.

Los descriptores se presentan de forma natural en los materiales audiovisuales. Los descriptores pueden ser de contenido o físicos. Los descriptores físicos registran los datos de título, duración y género. Según Santana y Carvalho (2012) los documentos presentan una serie de descriptores que facilitan su recuperación y localización dentro de un determinado grupo de materiales, los audiovisuales no son la excepción.

Los descriptores de contenido se operacionalizan en resumen, topográficos, cronológicos, temáticos, onomásticos y de forma. Arellano examina el descriptor resumen estableciendo que es una "breve descripción del contenido del documento. Se realiza una indización con vocabulario natural. Se plasma la sinopsis del documento completo" (2014, p. 9). Los descriptores de forma analizan el audiovisual y lo clasifican de acuerdo con el género del documento (spot, informativo, película, corto, musical, etc.). El investigador Gil (2008) describe el resto de los descriptores de contenido al establecer:

- Descriptores topográficos: nombres propios de lugares.

- Descriptores cronológicos: vocabulario controlado indicando periodos, fecha, etc.

- Descriptores temáticos: vocabulario controlado, que indique el asunto o tema.

- Descriptores onomásticos: nombres propios de personas.

Para la presente investigación solo se analizan los descriptores de contenido debido a que se enfoca en el contenido del material audiovisual para la realización televisiva comunitaria. Los descriptores físicos como "título, la mención de responsabilidad, la fecha de creación, el soporte, la duración, la colección y signatura topográfica" (Planas, 2007, p. 55), carecen de relevancia atendiendo a los objetivos del estudio. Los descriptores físicos por su parte, son más utilizados para la recuperación documental y el análisis de forma.

\section{PROPUESTA DOCUMENTAL PARA LA REALIZACIÓN TELEVISIVA COMUNITARIA}

En el procesamiento de la información de los documentos audiovisuales requiere del empleo de estos descriptores. El proceso de producción audiovisual facilita que los datos a contener por los materiales puedan ser intencionados y así se potencie la identificación del público al que se dirige. Se propone, por tanto, que se contemplen estos descriptores en la planificación de la construcción del audiovisual. El período de planificación es tan importante en el resultado final del producto audiovisual como la filmación y el proceso de preproducción. Debe considerarse la "existencia de observadores que, generalmente al final del proceso, se encargaban de aplicar los criterios de calidad" (Senso, Leiva y Domínguez, 2011, p. 340).

El proceso de producción televisiva debe iniciar con la selección del tipo de material que se propone realizar (informativo, musical, deportivo, dramatizados, variados, de facilitación social, entre otros), identificándose en la génesis el descriptor de forma. "La representación televisiva plantean un sesgo de complejidad en la interpretación de las formas e intereses subyacentes" (Galán y Rueda, 2014, p. 33), en este caso de la comunidad usuaria. Los descriptores cronológicos deberán indicar periodos, fechas y acontecimientos en sentido general; que sean de interés a los usuarios potenciales. Deberán reflejarse significativamente las conmemoraciones de la localidad, las fechas de celebración nacional, emplear de forma coherente las imágenes para reflejar períodos naturales o temporales que inciden de una $u$ otra forma en las actividades de la comunidad (de tipo cultural, económica, políticas, deportivas, entre otras).

Los descriptores topográficos deberán contener imágenes de lugares típicos de la comunidad, como paisajes urbanísticos, naturales, rurales, actividades socioeconómicas, actividades culturales y elementos que identifiquen la comunidad. Las imágenes o secuencias seleccionadas para la construcción de los audiovisuales deberán reflejar elementos propios del espacio físico que ocupa la comunidad. 
Los descriptores onomásticos deberán usarse para reflejar personas que son identificadas por los miembros de la comunidad o para legitimar otras de interés. Dado que la televisión comunitaria debe propiciar espacios para el reconocimiento colectivo, es importante propiciar espacios donde estén presentes autoridades, líderes populares y actores sociales relevantes de la comunidad. A decir de Márquez "de esta manera sería factible su reconocimiento social, y lograrían mayores transformaciones socioeconómicas y culturales para elevar su desarrollo" (2012, p. 128). También, formaría la "capacidad de relacionar los mensajes audiovisuales con otras formas de manifestación mediática y artística" (Ferrés, 2007, p. 10).

Los descriptores temáticos que se empleen en la televisión comunitaria deberán partir de necesidades de información que provengan de la localidad. El criterio de programación da nuevas perspectivas y refleja valores relacionados con la solidaridad, la educación, la valorización de local y la relocalización, el humanismo, el deseo de cambio, siempre tratando de incentivar un consumo crítico (Chaparro, 2009).

Ahora bien, para el empleo de este descriptor deberán tenerse en cuenta estudios de usuarios que identifiquen las necesidades de información (índices de delincuencia, cantidad de profesionales, protección del medio ambiente, mortalidad y natalidad infantil, esperanza de vida, riesgos epidemiológicos, niveles de pobreza, actividades socio-económicas fundamentales, entre otros). Además, deberán recogerse las necesidades informativas y televisivas de la población a partir de un estudio de usuarios o audiencia que facilite al realizador identificar temáticas para la solución de las demandas reales de la población, atrayendo mayor audiencia a los programas, debido a que "generalmente se confeccionan productos de información sin analizar las necesidades de los usuarios potenciales" (Caraballo y Martín, 2013, p. 57).

Al respecto, Soto (2008) corrobora que:

La Educación en Comunicación es un factor clave para capacitar a la ciudadanía en la interpretación crítica de los mensajes, para acceder, entender, gestionar y usar la información recibida, para ser actores sociales y no sujetos pasivos, para poner a su disposición las herramientas éticas con las que aprender a interpretar y reflexionar sobre la información y los modelos sociales que recibe (p. 525).

Por su parte, el descriptor resumen es el que describe el contenido del material. Por ello, se deberá elaborar uno previamente con la idea general del audiovisual por realizar. El metadato resumen a su vez, facilitará el análisis por parte de los usuarios o personas que deseen acceder a materiales audiovisuales y facilitará la recuperación de la información. El lenguaje por emplear deberá ser natural propiciando la comprensión del contenido de la fuente de información. El resumen debe expresarse de forma escueta, no descriptiva ni telegráfica, lo contenido en el plano (visual y audio — el audio que no está reflejado en las imágenes debe ir dentro de algún signo ortográfico que se haya acordado, y siempre se usará el mismo-); vocabulario preestablecido (siempre el mismo verbo para la misma acción, y siempre en gerundio) (Arellano, 2014). Por su lado, Caldera (2014) aboga por la necesidad de realizar el resumen documental en ciertos tipos documentales, cuando resulta innecesario en otros, consecuencia de la escasa duración.

\section{CONCLUSIONES}

La producción televisiva comunitaria debe partir de las necesidades de los usuarios o audiencia para quienes se produce. El desarrollo de estudios preliminares de tipo sociológico, económico, entre otros, facilitará identificar las necesidades reales de la comunidad.

La fase de planificación para la construcción de los documentos audiovisuales, es tan importante como la fase final o la transmisión. Los productores deben trazarse estrategias a fin de identificar las necesidades de los usuarios y convertir el canal comunitario en un agente socializador de la información. La planificación en la producción televisiva comunitaria debe emplear como estrategia, el uso de los descriptores propuestos desde el análisis documental de materiales audiovisuales; sirviendo de directrices a los realizadores.

Previo al diseño de un producto informativo deberán realizarse estudios de usuarios para la 
identificación de las necesidades de la comunidad. La identificación del comportamiento informacional de los usuarios o audiencia combinadas con el empleo consciente de descriptores de contenido propiciará que los productos audiovisuales resultantes sean cualitativamente superiores en cuanto a las iteraciones de las rutinas televisivas en beneficio de la comunidad usuaria.

Finalmente, el consumidor o interesado, ante la posibilidad de ser coproductor de los audiovisuales, reflejará sus aspiraciones y características y favorecerá (posteriormente) el consumo por la comunidad. El diseño de productos para satisfacer necesidades de información personalizadas por su parte, elevará los niveles de audiencia de la comunidad al verse reflejada. Así, el tránsito desde el crecimiento empírico hasta un grado de especialización superior, no perjudica la representación del imaginario popular y el cumplimiento de los estándares de calidad en la programación y la especialización en las rutinas televisivas, no afecta el objetivo esencial de la propuesta comunitaria.

\section{REFERENCIAS BIBLIOGRÁFICAS}

Aguaded, J. y Díaz, R. (2008). La formación de telespectadores críticos en educación secundaria. Revista Latina de Comunicación Social, 63, 121139.

Aguaded, J., Hernando, A. y Peréz, A. (2012). Pantallas en la sociedad audiovisual: edu-comunicación y nuevas competencias. Comunicação e Sociedade, 21, 217-229.

Arellano, M. C. (2014). Documentación Informativa, curso 2013-2014. Universidad Rey Juan Carlos. Recuperado de http://goo.gl/a13lcM.

Barthes, R. (1976). Introducción al análisis estructural del relato. Barcelona: Niebla.

Belimpasakis, P. y Saaranen, A. (2010). Sharing with people: a system for user-centric content sharing. Multimedia Systems, 6 (16), 399-421.

Cabrera, F., Donoso, T., Aneas, A. y del Campo, J. (2010). Valoración de la satisfacción de usuarios de programas sociales: propuesta de un modelo de análisis. Revista de Educación, 351, 311-336.

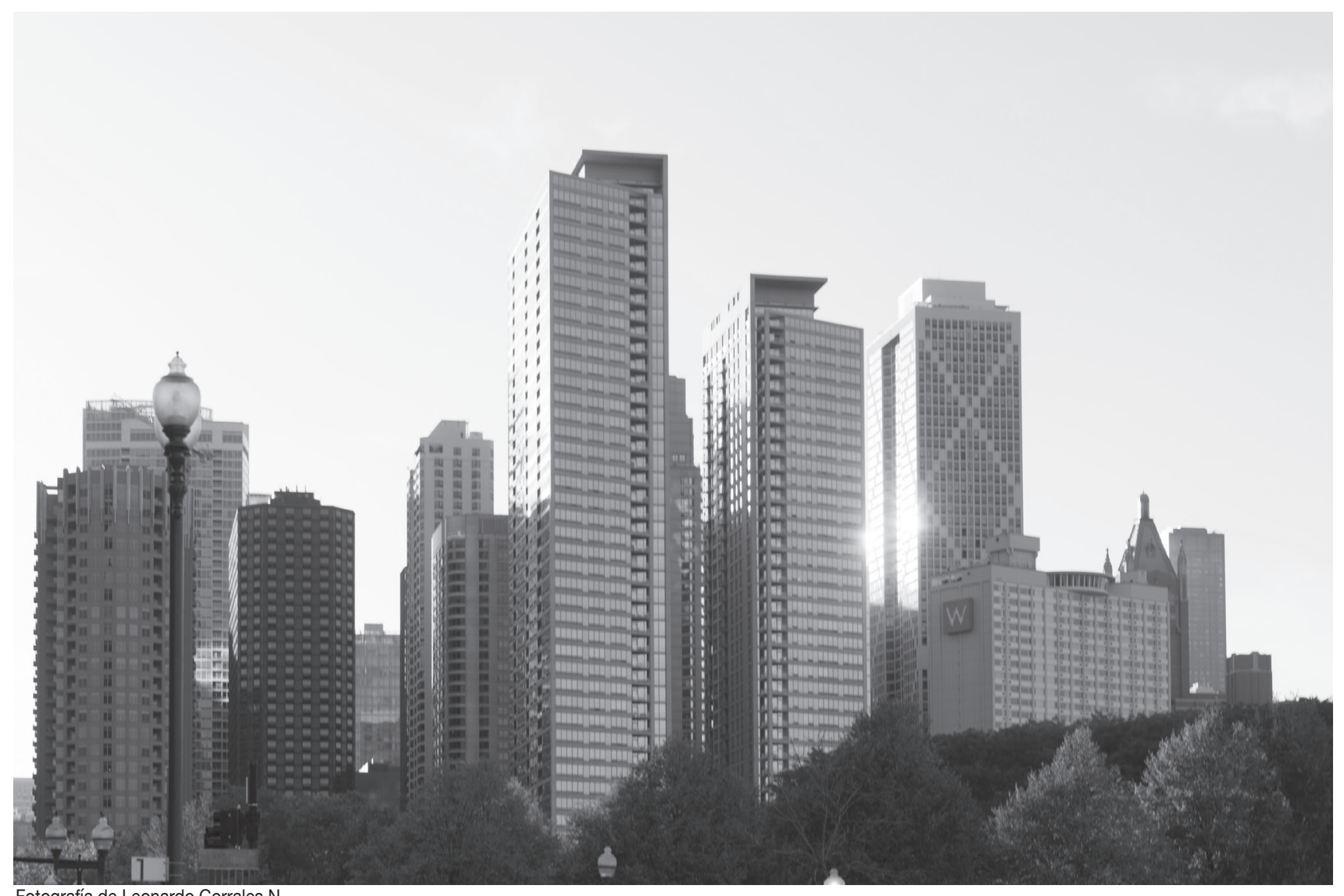

Fotografía de Leonardo Corrales N. 
Caldera, J. (2014). Resumiendo documentos audiovisuales televisivos: propuesta metodológica. Perspectivas em Ciencia da Informacao, 2(19), 147158.

Calva, J. (2013). Estudios de usuarios en diferentes comunidades: necesidades de información y comportamiento informativo. Instituto de Investigaciones Bibliotecológicas y de la Información: México.

Caraballo, F. y Martín, J. (2013). Estudio exploratorio de los modelos de publicación de tabletas: los sistemas de comunicación visual y de usabilidad. Comunicación y Sociedad, 3(26), 49-66.

Chaparro, M. (2009). Comunicación y empoderamiento ciudadano en Andalucía. Radios Públicas locales, participativas y ciudadanas. Chasqui, 108, 24-27.

Cloutier, J. (2001). Petit traité de communication. Montréal: Éditions Carte blanche.

Crawford, D. (1997). Information behaviour: An interdisciplinary perspective. Information Processing \& Management, 33 (4), 26-39.

Del Valle, F. (2014). La documentación en televisión. Recuperado de http://goo.gl/xHgMnQ.

Dervin, B. y Nilan, M. (1986). Information Needs and Uses. Annual Review of Informatios Science and Technology, 21 (1986), 1-33.

Feliú, E. (2000). La publicidad social. Universidad de Alicante: Alicante.

Fernández, F. (1994). Clase social, exposición a la televisión y percepción de la violencia en la televisión. Chile: Estudios Sociales.

Ferrés, J. (2007). La competencia en comunicación audiovisual: propuesta articulada de dimensiones e indicadores. Quaderns del CAC, 25, 9-17.

Figueredo, A. L., Figueredo, M. C. y Aponte, C. (2013). La biblioteca universitaria como institución de apoyo a la docencia y la investigación. Revista Bibliotecas. Anales de investigación, 31 (1), 1-8.

Galán, E. y Rueda, J. (2014). Cómo contar la historia. Estrategias de proximidad en la televisión argentina. Athenea Digital Revista de Pensamiento e Investigación Social, 14 (3), 23-47.
Gil, I. (2008). Manual de Indización. Teoría y Práctica. Trea: Asturias.

González, A. (2011). La perspectiva del usuario y del sistema en la investigación sobre el comportamiento informacional. Teoría de la Educación. Educación y Cultura en la Sociedad de la Información, 12 (1), 9-27.

Gumucio, A. (2008). La televisión comunitaria. Ni pulpo, ni púlpito: pálpito. Recuperado del sitio web: http://goo.gl/Ne8c4H.

Harter, J. y Busha, L. (1990). Metodología de la investigación en bibliotecología y Ciencia de la Información. Editorial Félix Varela: La Habana.

Harsh, A. y Mishra, J. K. (2012). Oh! Web 2.0, Virtual Reference Service 2.0, Tools \& Techniques (II). Journal of Library \& Information Services in Distance Learning, 6 (1), 149-171.

Hernández, A. (2007). Indización y Resumen. La Habana: Editorial Félix Varela.

Hernández Alfonso, E. A., Paz Enrique, L. E. y Jara Solenzar, D. (2016). Retos de la participación comunitaria en la producción televisiva local. Revista Universidad y Sociedad, 8, 147-152.

Herrera, Á. y Uruburu, S. (2010). La relación entre Comunicación y Desarrollo en Colombia. El aporte de la investigación de las Facultades de Comunicación entre 2000 y 2006. Signo y Pensamiento, 29 (56), 208-243.

Hjǿrland, B. y Albrechtsen, C. (2007). O conceito de informacao. Perspectivas em Ciencia da Informacao, 12 (1), 27-32.

Manso, R.A. (2012). Bibliotecas, fomento de la lectura y redes sociales: convirtamos amigos en lectores. El profesional de la información, 21 (4), 401405.

Márquez, L. (2012). Retos de la televisión comunitaria en Cuba, su papel en el desarrollo global. Communication Journal, 3, 121-135.

Márquez, L. (2013). Una TV verdaderamente comunitaria. Razón y Palabra, 82, 1-13.

Menéndez, M. y Hassan, S. (2007). Simulación Social basada en agentes software. Empiria: Madrid. 
Parra, J. (2006). Sintonizando la participación política en la televisión comunitaria. Palabra Clave, 9 (2), 67-76.

Pérez, M. (2002). Explotación de los córpora textuales informatizados para la creación de bases de datos terminológicas basadas en el conocimiento. Universidad de Málaga: Málaga.

Pinto, M., García, F. y Agustín, M. (2002). Indización y resumen de documentos digitales y multimedia: técnicas y procedimientos. Ediciones Trea: Asturias.

Planas, J. (2007). Documentos audiovisuales y prácticas laborales en las bibliotecas populares de La Plata. Un estudio de caso. Información, Cultura y Sociedad, 17, 51-67.

Prats, Joan. (2007). La competencia en comunicación audiovisual: dimensiones e indicadores. $\mathrm{CO}^{-}$ municar, 15 (29), 100-107.

Pynta, P., Seixas, S., Nield, G., Hier, J., Millward, E. y Silberstein, R. (2014). The Power of Social Television: Can Social Media Build Viewer Engagement? A New Approach to Brain Imaging of Viewer Immersion. Journal of Advertising Research, 54 (1), 71-80.

Raber, D. y Budd, J. M. (2003). Information as sign: Semiotics and Information Science. Journal of Documentation, 59 (5), 507-522.

Rendón, M.A. y Hernández, P. (2010). Sense-making: ¿metateoría, metodología o heurística? Revista Investigación Bibliotecológica, 24 (52), 61-81.

Retis, J. (2014). El rol de los medios en los procesos de estratificación social en el contexto migratorio. Chasqui, 125, 13-22.

Rey, C. (2000). La satisfacción del usuario: Un concepto en alza. Anales de Documentación, 3, 139153.
Rodrigo, M. y Lazcano, D. (2014). La enseñanza en comunicación y su proceso de adaptación al EEES como objeto de estudio: una visión panorámica. Comunicación y Sociedad, 27 (2), 221-239.

Santana, L. A. y de Carvalho, T. C. (2012). Uma discussão sobre documento audiovisual enquanto patrimônio arquivístico cultural no Brasil. Ibersid. 6, 179-185.

Santibáñez, J. (2010). Aula virtual y presencial en aprendizaje de comunicación audiovisual y educación. Comunicar, 18(35), 183-191.

Senso, J. A., Leiva, A. y Domínguez, S. (2011). Modelo para la evaluación de ontologías. Aplicación en Onto-Satcol. Revista Española de Documentación Científica, 34 (3), 334-354.

Senso, J. A., Magaña, P. J., Faber-Benitez, P. y Vila, M. M. (2007). Metodología para la estructuración del conocimiento de una disciplina: el caso de PuertoTerm. El profesional de la Información, 16, 591-604.

Soto, M. (2008). Educar la mirada y la escritura audiovisual. Comunicar, 16 (31), 523-527.

Urías, G. (2009). Metodología de la Investigación. Universidad Central "Marta Abreu" de las Villas: Santa Clara.

Van Dijk, T. (2004). Discurso y desigualdad. Universidad de La Laguna: Tenerife.

Wallerstein, I. (2006). Abrir las ciencias sociales. Madrid: Comisión Gulbenkian para reestructuración de las Ciencias Sociales.

Wang, X. y Klinc, R. (2012). Special issue: eLearning 2.0: Web 2.0-based social learning in built environment. Journal of Information Technology in Construction, 17, 386-387.

Wilson, T. D. (1999). Models in information behaviour research. Journal of Documentation, 55 (3), 249-270. 